\title{
The rate of success of the conservative management of liver trauma in a developing country
}

\author{
S. Buci ${ }^{*}$ (D) M. Torba ${ }^{1}$, A. Gjata ${ }^{2}$, I. Kajo ${ }^{3}$, Gj. Bushi ${ }^{1}$ and K. Kagjini ${ }^{1}$
}

\begin{abstract}
Background: The conservative treatment of liver trauma has made important progress over the last 10 years at the Trauma University Hospital in Tirana, Albania. The percentage of success was $58.7 \%$. The aims of this study were to analyze the conservative treatment of liver trauma and to compare the results with those in the literature.

Methods: This study was conducted prospectively from January 2009 to December 2012. We analyzed 173 patients admitted to our hospital with liver trauma. Liver injuries were evaluated according to the American Association for the Surgery of Trauma and the World Society of Emergency Surgery classification, while the anatomic gravity of the associated injuries was defined using the Injury Severity Score system. The potential mortality was estimated with the Revised Trauma Score.

Results: Out of the 173 patients with liver trauma, 83.2\% were male. The main cause of liver trauma was motor vehicle crashes (50.9\%). Blunt trauma was the cause of liver injury in 129 cases (74.6\%), and penetrating trauma occurred in 44 cases (25.4\%). Initially, the decision was to manage 88 cases (50.9\%) via the conservative approach. Of these, 73 cases (42.2\%) were successfully treated with conservative treatment, while in 15 cases (17.2\%), this approach failed. The success rate of conservative treatment by grade of injuries was as follows: grade I (38.4\%), grade II (30.1\%), grade III (28.8\%), and grade IV (2.7\%). The likelihood of the success of conservative treatment had a significant correlation with the grade of the liver injury $(p<0.00001)$, associated intra-abdominal injuries $(p=0.00051)$, and complications ( $z=2.3169, p=0.02051$ ). The overall mortality rate of liver trauma was $13.2 \%$.

Conclusions: The likelihood of success in using conservative treatment had a significant correlation with the grade of liver injury and associated intra-abdominal injuries. The limited hospital resources and low level of consensus on conservative treatment had a negative impact on the level of success.
\end{abstract}

Keywords: Liver trauma, Grade of injuries, Conservative treatment, Success

\section{Background}

Currently, the conservative management of liver trauma is considered the "Gold Standard." More than $80 \%$ of patients with non-severe liver injuries are treated successfully without surgery [1-4]. Nance and Cohn support the use of conservative treatment in hemodynamically stable patients who do not exhibit signs of peritoneal irritation [5]. In Albania, the conservative treatment of liver trauma has made important progress over the last decade. The diagnostic and therapeutic strategy for liver

\footnotetext{
* Correspondence: buciskender@gmail.com

${ }^{1}$ Service of General Surgery, Trauma University Hospital, Tirana, Albania

Full list of author information is available at the end of the article
}

injury depends on the hemodynamic status of the traumatized patients and the associated injuries.

The World Society of Emergency Surgery (WSES) liver trauma classification considers not only the anatomic American Association for the Surgery of Trauma (AAST) classification but also, more importantly, the hemodynamic status and the associated injuries [6] (Table 1).

The abdominal echography procedure is essential in the emergency department for patients with hemodynamic instability. Currently, computerized tomography is the preferred method to evaluate blunt liver trauma in hemodynamically stable patients or in patients who have been stabilized after an initial fluid resuscitation [7]. 
Table 1 WSES liver trauma classification

\begin{tabular}{|c|c|c|c|c|c|c|}
\hline & WSES grade & $\begin{array}{l}\text { Blunt/penetrating } \\
\text { (stab/guns) }\end{array}$ & AAST & Hemodynamic & CT scan & First-line treatment \\
\hline \multirow[t]{2}{*}{ Minor } & WSES grade I & $B / P$ & $|-| \mid$ & Stable & & \\
\hline & & SW/GSW & & & & \\
\hline \multirow[t]{2}{*}{ Moderate } & WSES grade ॥ & $B / P$ & III & Stable & Yes & $\mathrm{NOM}^{*}$ \\
\hline & & SW/GSW & & & Local Exploration in SW & $\begin{array}{l}\text { Serial Clinical/Laboratory/ } \\
\text { Radiological Evaluation }\end{array}$ \\
\hline \multirow[t]{4}{*}{ Severe } & WSES grade III & $B / P$ & IV-V & Stable & & \\
\hline & & SW/GSW & & & & \\
\hline & WSES grade IV & $B / P$ & $|-\mathrm{V}|$ & Unstable & No & $\mathrm{OM}$ \\
\hline & & SW/GSW & & & & \\
\hline
\end{tabular}

SW stab wound, GSW gunshot wound, OM operative management, ${ }^{*}$ NOM non-operative management

The conservative treatment of liver injury can be initiated when there is a possibility of monitoring the traumatized patient clinically, biologically, and radiologically in the correct manner and when there is a close collaboration between surgeons, intensivists, and radiologists. The failure of conservative treatment occurs in 15\% of cases, often in patients with extrahepatic injuries or white laparotomy $[8,9]$.

The objectives of this study were to analyze the conservative management of liver trauma, the likelihood for success, and the causes of failure and to compare the results with those in the literature.

\section{Methods}

This is a prospective study performed from January 2009 to December 2012. We analyzed 173 patients with hepatobiliary trauma who were admitted to the Trauma University Hospital, Tirana, Albania. Liver injuries were evaluated according to AAST and WSES classifications via ultrasonography and CT scan. The anatomic gravity of the associated injuries was defined using the Injury Severity Score (ISS) system. The potential mortality was estimated using the Revised Trauma Score (RTS). A simple ordinary least square regression (OLS) of several factors on the success of conservative treatment of trauma injury patient reveals the results of the following table. For this analysis, the variables are Surviv (whether the patient survives the treatment of the injury $[\mathrm{No}=0$; Yes $=1]$ ); Age (age of the patient $[6-15$ years old $=1$; $16-25$ years old $=2 ; 26-35$ years old $=3 ; 36-45$ years old $=4 ; 46-55$ years old $=5$; $56-65$ years old $=6$; 6675 years old $=7]$ ); Gender (gender $[$ Male $=1$; Female = $0]$ ); Cinjur (if only the liver is injured, then the value is 0 . For all other combinations, like the liver and head and the liver and thorax, the variable takes the value of 1); Grade (grade [the six-grade scale standard is used: Minor $=1$; Moderate $=2$; Serious $=3$; Severe $=4$; Critical $=5$; Un-survivable $=6]$ ); Conserv (conservative treatment of the patient [Yes $=1 ; \mathrm{No}=0]$ ); Interv (the patient is treated with an intervention [Yes $=1 ; \mathrm{No}=0$ ]); ISS (anatomical; the higher the number, the more severe the injury); and RTS (psychological; the lower the number, the more severe the condition of the patient).

Treatment for each patient was chosen based on the set of indicators for laparotomy and under the consideration for conservative treatment. The indicators were (1) hemodynamic stability, (2) presence/absence of peritoneal irritation signs, (3) identification and evaluation of CT scan grade of liver injuries, (4) hemoperitoneum $<500 \mathrm{ml}$, and (5) the absence of injury to cavitare organs $[10,11]$, based on the algorithm for the non-operative management of blunt hepatic trauma [12].

Based on these criteria, patients were divided into two main groups: group A (including 88 patients who met the conditions for conservative treatment) and group $B$ (including 85 patients who had indications for immediate laparotomy).

\section{Results}

The average age of patients with hepatic trauma was 23.4 years old (ranging from 6 to 75 ), including 83.2\% male and $16.8 \%$ female patients.

In our study, blunt trauma was the cause of liver injury in 129 cases $(74.6 \%)$, while penetrating trauma occurred in 44 cases (25.4\%).

The causes of hepatic trauma were motor vehicle crashes in 88 cases (50.9\%), falls from height in 32 cases (18.4\%), gunshot wounds in 24 cases $(13.8 \%)$, sharp tools in 19 cases $(11 \%)$, direct blows in 8 cases (4.7\%), iatrogenic in 1 case $(0.6 \%)$, and hepatic trauma from an electrical arc in 1 case (0.6\%) (Tables 2 and 3).

Alanine aminotransferase (ALT) $>100 \mathrm{U} / \mathrm{l}$ and aspartate aminotransferase (AST) $>200 \mathrm{U} / \mathrm{l}$ were found in 96 patients (55.5\%), and ALT >1000 U/l and AST >1100 U/ 1 were found in 2 patients (1.6\%).

Diagnostic peritoneal lavage (DPL) was used in10 patients (5.6\%). In 6 patients, we found intestine leak. 
Table 2 Hemodynamic status

\begin{tabular}{lll}
\hline Initial hemodynamic status & No. of patients & Percentage \\
\hline Hemodynamic instability & 47 & 27.1 \\
$\begin{array}{l}\text { Stabilized after intravenous } \\
\text { liquid administration }\end{array}$ & 84 & 48.6 \\
Hemodynamic stability & 42 & 24.3 \\
\hline
\end{tabular}

In our study, 62 patients $(35.9 \%)$ were transfused with 1 unit of blood, 41 (23.8\%) were transfused with 2 units, 30 (17.9\%) were transfused with 3 units, 22 (12.8\%) were transfused with 4 units, and 17 (9.6\%) were transfused with more than 4 units (Table 4 ).

The injury frequencies, according to the Couinaud segment, were as follows: I segment $(n=8) 2.5 \%$, II segment $(n=10) 3.1 \%$, III segment $(n=16) 5 \%$, IV segment $(n=32) 10 \%$, V segment $(n=49) 15.3 \%$, VI segment $(n=$ 76) $23.8 \%$, VII segment $(n=65) 20.3 \%$, and VIII segment ( $n=64) 20 \%$.

The frequency of liver injury according to the WSES were WSES grade I $(n=65) 37.6 \%$, WSES grade II $(n=$ 55) $31.8 \%$, WSES grade III $(n=6) 3.5 \%$, and WSES grade IV $(n=47) 27.1 \%$.

Isolated hepatic injuries were detected in 45 cases (26.1\%), and combined hepatic injuries were present in 128 cases $(73.9 \%)$.

Hepatic injuries were associated with intra-abdominal hollow organ injuries in 33 cases (19.1\%) and with parenchymal injuries in 31 cases (17.9\%) (Table 5).

Hepatic injuries were associated with extra-abdominal injuries, including the head in 27 cases (15.6\%), the thorax and diaphragm in 80 cases $(46.2 \%)$, the heart in 2 cases $(1.2 \%)$, the vertebral column in 3 cases $(1.7 \%)$, pelvic fracture in 12 cases (6.9\%), and limb fractures in 19 cases (11\%) (Tables 6 and 7).

In group A (conservative treatment of 88 patients), 73 patients (42.2\%) benefitted from successful conservative treatment. Unsuccessful conservative treatment due to further complications was seen in 15 patients (17.2\%). In patients with isolated liver injuries, conservative treatment was successful in 27 cases (58.7\%).

In group B, 100 patients underwent laparotomy. An immediate laparotomy was performed in 85 patients (49.1\%), a laparotomy for hepatic injury was performed in 30 patients $(30 \%)$, laparotomy for extrahepatic injury was performed in 70 patients $(70 \%)$, perihepatic packing was performed in 10 patients $(11.7 \%)$, and relaparotomy

Table 3 Hematocrit level (at the time of arrival in the ER)

\begin{tabular}{lll}
\hline Initial hematocrit level & No. of patients & Percentage \\
\hline Up to 37 & 124 & 71.7 \\
$37-30$ & 34 & 19.7 \\
Under 30 & 15 & 8.6 \\
\hline
\end{tabular}

Table 4 Hepatic injuries according to AAST grade

\begin{tabular}{llc}
\hline Grade & Number of cases & Percentage \\
\hline I & 36 & 20.8 \\
II & 60 & 34.7 \\
III & 47 & 27.2 \\
IV & 21 & 12.1 \\
V & 8 & 4.6 \\
VI & 1 & 0.6 \\
\hline
\end{tabular}

was performed in 6 patients (7\%). Extrahepatic injuries included the stomach $(n=10,12.3 \%)$, the small intestine and duodenum $(n=12,14.8 \%)$, the large intestine and rectum $(n=9,11.1 \%)$, the spleen $(n=16,19.7 \%)$, the kidneys $(n=12,14.8 \%)$, the pancreas $(n=4,4.9 \%)$, the diaphragm $(n=35,43.2 \%)$, the intra-abdominal esophagus ( $n=1,1.2 \%)$, the cholecyst $(n=3,3.7 \%)$, and the urinary bladder $(n=2,2.5 \%)$.

We observed that $10.9 \%$ of the patients who were treated in a conservative manner had an ISS of $\geq 20$. We also observed that in this group of patients, $86.3 \%$ had an RTS of $>5$ (Tables 8, 9, 10, and 11).

The chances of successful conservative treatment significantly depend on the grade of liver injury $(p<$ $0.00001)$. There is also a statistically significant connection between the successful conservative treatment of liver trauma and a combination of injuries with other organs $(p$ value $=0.00051)$ and complications $(z=2.3169$, $p=0.02051$ ) (Table 12).

The OLS shows that the patient age, gender, combined injury, and grade of injury (anatomical, physiological, and locational) account for more than $30 \%$ of the variation in the success of conservative treatment (as seen with an adjusted $R$-squared $=0.319$ ). From the variables under consideration, it is clear that patient age, combination of injuries with other organs besides the liver,

Table 5 The mechanism of trauma and associated abdominal injuries

\begin{tabular}{llllr}
\hline Organ & $\begin{array}{l}\text { Blunt } \\
\text { trauma }\end{array}$ & $\begin{array}{l}\text { Penetrating } \\
\text { trauma }\end{array}$ & Total & Percentage \\
\hline Spleen & 14 & 2 & 16 & 9.2 \\
Kidneys & 9 & 3 & 12 & 6.9 \\
Pancreas & 2 & 2 & 4 & 2.3 \\
Stomach & 3 & 7 & 10 & 5.8 \\
Small intestine + & 3 & 9 & 12 & 6.9 \\
duodenum & & & & \\
Large intestine + & 3 & 6 & 9 & 5.2 \\
rectum & & & & \\
Diaphragm & 8 & 27 & 35 & 20.2 \\
Esophagus & 0 & 1 & 1 & 0.6 \\
Urinary bladder & 1 & 0 & 2 & 1.2 \\
Total & 43 & 57 & 100 & 58.3 \\
\hline
\end{tabular}


Table 6 Success of conservative management according to AAST grade

\begin{tabular}{lll}
\hline Grade & Number of cases & Percentage \\
\hline I & 28 & 38.4 \\
II & 22 & 30.1 \\
III & 21 & 28.8 \\
IV & 2 & 2.7 \\
V & 0 & 0 \\
VI & 0 & 0
\end{tabular}

grade of injury, and RTS (psychological trauma) are statistically important. This is verifiable from the above table that presents both the $p$ values and the $t$ values.

The overall mortality rate of liver trauma was $13.2 \%$.

\section{Discussion}

Our study demonstrated that liver injuries occurred in $17 \%$ of patients with abdominal trauma. Shanmuganathan et al. have reported that liver injuries occurred in $20 \%$ of patients with blunt abdominal trauma [13]. We found that male to female ratio was $5: 1$. Beel et al. found that the male to female ratio varies from 15:1 [14]. Approximately 15-20 years ago, all traumatic liver injuries were treated surgically, but in $50-80 \%$ of cases, no active bleeding was found $[15,16]$. We also found liver injuries with no active bleeding during laparotomy for associated injuries.

In our study, the hemodynamic status was the main criterion in determining the therapeutic approach. Approximately $85 \%$ of patients with blunt liver trauma are hemodynamically stable or stabilize after receiving intravenous liquids [17], which corresponds with the findings in our study. Richardson et al. commented that many experienced surgeons in trauma surgery apply surgical treatment in hemodynamically stable patients and they have concluded that conservative treatment has a positive impact on patient survival [18]. In hemodynamically stable patients, a helical CT examination with oral and venous contrast was performed to determine the grade of the liver injury, the amount of hemoperitoneum, the presence of pseudoaneurysms, and the presence of other intraperitoneal injuries.

Hemoperitoneum was observed in repeated ultrasound examinations, and in some cases, re-evaluation was done via CT scan. Malhotra et al. reports that a large amount of hemoperitoneum (when blood is present in the lateral

Table 7 Management according the WSES grade

\begin{tabular}{lcr}
\hline WSES & Conservative & Laparotomy \\
\hline WSES grade I & $50(76.9 \%)$ & $15(23.1 \%)$ \\
WSES grade II & $21(38.2 \%)$ & $34(61.8 \%)$ \\
WSES grade III & $2(33.3 \%)$ & $4(66.7 \%)$ \\
WSES grade IV & $0(0 \%)$ & $47(100 \%)$ \\
\hline
\end{tabular}

Table 8 The causes of failure of conservative treatment

\begin{tabular}{llc}
\hline Complications & No. of patients & Percentage \\
\hline Secondary hemorrhage & 3 & 3.4 \\
Biliary peritonitis & 2 & 2.3 \\
Intrahepatic biloma & 1 & 1.1 \\
Extrahepatic biloma & 2 & 2.3 \\
Hollow organ injuries & 2 & 2.3 \\
Liver compartment syndrome & 1 & 1.1 \\
Gangrenous cholecystitis & 2 & 2.3 \\
Peritoneal inflammatory syndrome & 2 & 2.3 \\
Total & 15 & 17.2 \\
\hline
\end{tabular}

channels, the perihepatic space, and the Douglas pouch) is a significant risk factor for the failure of conservative treatment [19]. Due to limited resources for transfusion in our hospital, we interrupted conservative treatment in patients who had a considerable need for transfusion and when the amount of hemoperitoneum was determined to be progressively increasing.

From group A of 88 patients selected for conservative management, 15 patients showed complications that necessitated surgery. Group B consisted of 85 patients who underwent immediate laporatomy due to the following indications: hemodynamic instability, associated intraabdominal injuries, and penetrating trauma. It is worth emphasizing that a case with penetrating liver trauma caused by hunting rifle wounds was managed conservatively. Ten patients underwent perihepatic packing; of these, a second laparotomy was performed in 6 patients and 4 patients did not survive.

In our study, we found that gunshot wounds and wounds caused by sharp tools had an incidence of $24.8 \%$.

This percentage was significant and contributed to a reduction in the number of patients managed conservatively. The gunshot wounds were penetrating in 35-70\% of cases [20], and the wounds caused by sharp tools were not penetrating in $35-61 \%$ of cases $[21,22]$.

Diagnostic peritoneal lavage (DPL) is another valid tool to determine the presence or nature of intraperitoneal liquids. We used this procedure in a few cases. DPL, described by Root in 1965, remains an important tool in the

Table 9 Complications of conservative treatment of patients with combined liver trauma according to some authors

\begin{tabular}{lll}
\hline Complications & References & Our study (\%) \\
\hline Secondary hemorrhage & $5 \%[30]$ & 3.4 \\
Missed injuries & $3-5 \%[28,35]$ & 2.3 \\
Hemobilia & $0.3-1.2 \%[36,37]$ & 1 \\
Bilhemia & $0.2-1 \%[38]$ & 1 \\
Bile leakage & $3-20 \%$ & 6.8 \\
\hline
\end{tabular}


Table 10 Comparative data on secondary indications for surgical treatment after an initial determination to perform conservative treatment

\begin{tabular}{lll}
\hline $\begin{array}{l}\text { Secondary indications for } \\
\text { surgical treatment }\end{array}$ & $\begin{array}{l}\text { Letoublon et al. } \\
(186 \text { patients) (\%) }\end{array}$ & $\begin{array}{l}\text { Our study } \\
(173 \text { patients) (\%) }\end{array}$ \\
\hline $\begin{array}{l}\text { Peritoneal inflammatory } \\
\text { syndrome }\end{array}$ & 5.5 & 2.3 \\
$\begin{array}{l}\text { Secondary hemorrhage } \\
\text { Liver compartment }\end{array}$ & 1 & 3.4 \\
syndrome & 1 & 1.1 \\
Hollow organ injuries & 1 & 2.3 \\
Biliary peritonitis & 0.5 & 2.3 \\
Extrahepatic biloma & 0 & 2.3 \\
Post-traumatic cholecystitis & 0 & 2.3 \\
Intrahepatic biloma & 0 & 1.1 \\
Bilothorax & 0.5 & 0 \\
Abdominal compartment & 1 & 0 \\
syndrome & & 0 \\
Post-traumatic pancreatitis & 0.5 & \\
\hline
\end{tabular}

hands of surgeons, especially in the absence of minimally invasive equipment. DPL has a very high sensibility and specificity rate for intraperitoneal injuries, 95 and 99\%, respectively. However, this procedure is associated with complications in $0.8-1.7 \%$ of cases [23].

Our study showed that conservative treatment turned out to be successful in $42.2 \%$ of patients with combined hepatic trauma and in $58.7 \%$ of patients with isolated hepatic trauma. These percentages recorded in our study are lower than those reported elsewhere. It is our view that these differences are related to two factors: (1) a low level of consensus for conservative management and (2) limited hospital resources (limited interventional radiology procedures). Conservative treatment failed in $17.2 \%$ of cases. In some studies, it has been reported that

Table 11 Frequencies of several variables for both treatment modes (conservative and laparotomy)

\begin{tabular}{lcr}
\hline Variable & Conservative & Laparotomy \\
\hline Male & $61(42.4 \%)$ & $83(57.6 \%)$ \\
Female & $12(41.4 \%)$ & $17(58.6 \%)$ \\
$>55$ years old & $8(57.1 \%)$ & $6(42.9 \%)$ \\
$<55$ years old & $65(40.9 \%)$ & $94(59.1 \%)$ \\
ISS $>20$ & $8(8.8)$ & $83(91.2 \%)$ \\
ISS $<20$ & $65(79.3 \%)$ & $17(20.7 \%)$ \\
RTS $>5$ & $63(63.6 \%)$ & $36(36.4 \%)$ \\
RTS $<5$ & $10(13.5 \%)$ & $64(86.5 \%)$ \\
$\leq$ Grade IV & $73(42.1 \%)$ & $100(57.9 \%)$ \\
$>$ Grade IV & $0(0 \%)$ & $9(100 \%)$ \\
Complications & $15(20.5 \%)$ & $11(11 \%)$ \\
Mortality & $1(1.4 \%)$ & $12(12 \%)$ \\
\hline
\end{tabular}

Table 12 OLS, "success of the conservative management" as the dependent variable

\begin{tabular}{lcllc}
\hline Variables & Coefficient & Std. error & $t$ ratio & $p$ value \\
\hline Const & -0.233669 & 0.311065 & -0.7512 & 0.4536 \\
Age & 0.0493656 & 0.0196583 & 2.5112 & 0.0130 \\
Gender & 0.0253333 & 0.0731743 & 0.3462 & 0.7296 \\
Cinjur & 0.136536 & 0.0745459 & 1.8316 & 0.0688 \\
Grade & 0.0414623 & 0.0336495 & 1.2322 & 0.2196 \\
Resec & -0.151871 & 0.134283 & -1.1310 & 0.2597 \\
ISS & -0.0124758 & 0.0027189 & -4.5885 & $<0.0001$ \\
RTS & 0.0892609 & 0.0315478 & 2.8294 & 0.0052 \\
Mean dependent var. & 0.445087 & S.D. dependent var. & 0.498418 \\
Sum-squared resid. & 27.91268 & S.E. of regression & 0.411300 \\
R-squared & 0.346740 & Adjusted $R$-squared & 0.319026 \\
\hline
\end{tabular}

the efficacy of conservative management of liver trauma in hemodynamically stable patients is between 87 and $98 \%$, and the failure rate is between 10 and $25 \%$ [24, 25].

Injuries that were grade III or worse added substantially to the failure of conservative management. We had only two patients with grade IV liver injury that were successfully managed conservatively. Malhotra et al. found that in $14 \%$ of patients with grade IV injuries and $22.6 \%$ of patients with grade $\mathrm{V}$ injuries, conservative treatment was not successful, and the failure rate in patients with grades I, II, and III injuries was 3-7 and 5\% [19]. The likelihood of the success of conservative treatment had a significant correlation with the grade of liver injury. The coefficient of grade injury was -2.6 , which means that for every increase in the grade of the injury, the likelihood of the success of conservative treatment drops to 2.6. In addition, the success of conservative treatment had a significant correlation with associated intra-abdominal injuries. Other factors were statistically insignificant in the success of the conservative treatment.

The failure of the conservative treatment was often attributed to the deterioration of hemodynamic parameters, bile leakage, and the presence of overlapping septic complications. Durham et al. and Hammond et al. have reported that secondary hemorrhage occurs in less than $5 \%$ of cases treated conservatively [26, 27]. We observed that the failure of conservative treatment due to secondary hemorrhage occurred in 3\% of cases. Buckman et al. showed that bile leakage can occur in $3-20 \%$ of patients who are managed conservatively $[28,29]$. The frequency of hemobilia, as reported by Croce et al. and Walt et al., ranges from 0.3 to $1.2 \%$ [28, 30]. A rare complication, such as bilhemia, occurs in less than $1 \%$ of patients with hepatic trauma [31]. Bilhemia is determined by the presence of pseudoaneurysm (that is found in angio CT), increased bilirubin level, and a normal level of liver enzymes (ALT, 
AST). We found the same frequency of bilhemia and hemobilia. Subcapsular hematoma should be surgically treated only for two reasons: (1) to increase the value of ALT and AST and (2) if the patient has Budd-Chiari syndrome [32, 33]. In our study, only one patient underwent surgical intervention due to increases in ALT and AST values.

The incidence of failure of conservative treatment due to associated intra-abdominal injuries has been reported to be between 0.5 and $3.5 \%[11,34]$, whereas in our study, the failure rate with associated intra-abdominal injuries was $2.3 \%$.

\section{Conclusions}

The likelihood of the success of conservative treatment has a significant correlation with the grade of liver injury and associated intra-abdominal injuries. Limited hospital resources and the low level of consensus for nonsurgical management have a negative impact on the outcome. The main causes of failure are secondary hemorrhage and bile leakage.

\section{Acknowledgements}

The authors are very grateful to the staff of the Trauma University Hospital in Tirana, who have been generous and supportive throughout the conduction of this research.

\section{Funding}

This research did not use any internal or external funds.

Availability of data and materials

Please contact the authors for data requests.

\section{Authors' contributions}

BS designed the study and methodology, participated in gathering the data, and conducted the analysis. TM provided the literature review, participated in the data collection, and contributed to the statistical analysis. GA participated in the methodology and provided insights for the WSES classification system. KI evaluated the diagnosis and complications and provided important insights for the data classification. BG contributed to the data collection and provided systematic assistance in crafting the analysis. KK contributed to the data classification and the interpretation of the results. All authors read and approved the final manuscript.

\section{Competing interests}

The authors declare that they have no competing interests.

\section{Consent for publication}

Not applicable.

\section{Ethics approval and consent to participate}

A group of authors led by Dr. Skender Buci applied to the Committee of Ethics at the University of Medicine to evaluate the ethical appropriateness of the research "The rate of success in conservative management of liver trauma in a developing country." The Committee found that the conduct of research, data collection, and usage was in accordance with ethical principles and procedures. Rector, Arben Gjata.

\section{Publisher's Note}

Springer Nature remains neutral with regard to jurisdictional claims in published maps and institutional affiliations.

\section{Author details}

${ }^{1}$ Service of General Surgery, Trauma University Hospital, Tirana, Albania.

2Department of Surgery, UHC "Mother Teresa", Tirana, Albania. ${ }^{3}$ Department of Internal Medicine, Trauma University Hospital, Tirana, Albania.

Received: 7 February 2017 Accepted: 22 May 2017

Published online: 07 June 2017

References

1. Petrowsky H, Raeder S, Zuercher L, et al. A quarter century experience in liver trauma: a plea for early computed tomography and conservative management for all hemodynamically stable patients. World J Surg. 2012;36: 247-54

2. Leppäniemi AK, Mentula PJ, Streng MH, et al. Severe hepatic trauma: nonoperative management, definitive repair, or damage control surgery? World J Surg. 2011;35:2643-9.

3. Polanco PM, Brown JB, Puyana JC, et al. The swinging pendulum: a national perspective of nonoperative management in severe blunt liver injury. J Trauma Acute Care Surg. 2013;75:590-5.

4. Piper GL, Peitzman AB. Current management of hepatic trauma. Surg Clin North Am. 2010;90:775-85.

5. Pruvot F, Meaux F, Truant $\mathrm{S}$, et al. Traumatismes graves fermés du foie: à la recherche de critères décisionnels pour le choix du traitement non opératoire. A propos d'une série de 88 cas. Ann Chir. 2005;130:70-80.

6. Coccolini F, Catena F, Moore EE, et al. WSES classification and guidelines for liver trauma. World J Emerg Surg. 2016:10(11):50. eCollection 2016.

7. Fabian TC, Bee TK. Ch 32. Liver and biliary tract. In: Feliciano DV, Mattox KL, Moore EE, editors. Trauma. 6th ed. Pennsylvania Plaza: The McGraw-Hill Companies, Inc; 2008. p. 637-58.

8. Velmahos G, Toutouzas K, Radin R, et al. High success with nonoperative management of blunt hepatic trauma: the liver is a sturdy organ. Arch Surg. 2003;138:475-81.

9. Nance FC, Cohn I. Surgical judgement in the management of stab wounds of the abdomen: a retrospective and prospective analysis based on a study of 600 stabbed patients. Ann Surg. 1969;170:569-80.

10. Pachter HL, Hofstetter SR. The current status of nonoperative management of adult blunt hepatic injuries. Am J Surg. 1995:169:442-54.

11. Carrillo EH, Platz A, Miller FB, et al. Non-operative management of blunt hepatic trauma. Br J Surg. 1998:85:461-8.

12. Kozar RA, Moore FA, Moore EE, West M, Cocanour CS, Davis J, Biffl WL, McIntyre RC Jr. Western Trauma Association critical decisions in trauma: nonoperative management of adult blunt hepatic trauma. J Trauma. 2009; 67:1144-8.

13. Shanmuganathan $\mathrm{K}$, Mirvis SE. CT evaluation of the liver with acute blunt trauma. Crit Rev Diagn Imaging. 1995;36:73-113.

14. Meel BL. Incidence and patterns of violent and/or traumatic deaths between 1993 and 1999 in the Transkei region of South Africa. J Trauma. 2004:57:125-9.

15. Mirvis S, Whitley N, Vainwright J, et al. Blunt hepatic trauma in adults: CTbased classification and correlation with prognosis and treatment. Radiology. 1989:171:27-32

16. Croce M, Fabian T, Menke $P$, et al. Nonoperative management of blunt hepatic trauma is the treatment of choice for hemodynamically stable patients. Results of a prospective trial. Ann Surg. 1995;221:744-55.

17. Fabian TC, Bee TK. Ch 31. Liver and biliary tract trauma. In: Moore EE, Felliciano DV, Mattox KL, editors. Trauma, 5th ed. Pennsylvania Plaza: The McGraw-Hill, Companies, Inc; 2004. p. 637-58

18. Richardson JD, Franklin GA, Lukan JK, et al. Evolution in the management of hepatic trauma: a 25-year perspective. Ann Surg. 2000;232:324-30.

19. Malhotra A, Fabian T, Croce $M$, et al. Blunt hepatic injury: a paradigm shift from operative to nonoperative management in the 1990's. Ann Surg. 2000; 231:804-13.

20. Brinquin L, Borne M, Debien B, Clapson P, Jault P. Traumatismes balistiques: les lesions abdomino-pelviennes. Paris: Elsevier; 2008. p. 533-41.

21. Leonard D, Rebiel N, Perez M, Duchamp C, Grosdidier G. The place of laparoscopy in the management of the patients with penetrating abdominal trauma. J Chir. 2007:144:421-4

22. Kopelman TR, O Neil PJ, Macias LH, Cox JC, Mathews MR, Drachman DA. The utility of diagnostic in the evaluation of anterior abdominal stab wounds. Am J Surg. 2008;196:871-7.

23. Nagy KK, Roberts RR, Joseph KT, et al. Experience with over 2500 diagnostic peritoneal lavages. Injury. 2000;31:479-82. 
24. Trunkey DD. Hepatic trauma: contemporary management. Surg Clin North Am. 2004;84:437-50.

25. Christmas AB, Wilson AK, Manning B, et al. Selective management of blunt hepatic injuris including nonoperative management is a safe and effective strategy. Surgery. 2005;138:606-11.

26. Durham R, Buckley J, Keegan M, et al. Management of blunt hepatic injuries. Am J Surg. 1992;164:477-81.

27. Hammond J, Canal D, Broadie T. Nonoperative management of adult blunt hepatic trauma in a municipal trauma center. Am Surg. 1992;58:551-6.

28. Arikan $S$, Kocakusak A, Yucel AF, Adas $G$, et al. A prospective comparison of the selective observation and routine exploration method for penetrating abdominal stab wounds with organ or omentum evisceration. J Trauma. 2005:58:526-32

29. Buckman RJ, Piano G, Dunham C, et al. Major bowel and diaphragmatic injuries associated with blunt spleen or liver rupture. J Trauma. 1988;28: $1317-21$.

30. Suleman ND, Rasoul HA. War injuries of the chest. Injury. 1985;16:382-4.

31. Clemens M, Wittrin G. Bilhämie und hämobilie nach Reitunfall, Vortrag 166 1975. Tagung Nordwestdeutscher Chirurgen.

32. Markert DJ, Shanmuganathan K, Mirvis SE, et al. Budd-Chiari syndrome resulting from intrahepatic IVC compression secondary to blunt hepatic trauma. Clin Radiol. 1997;52:384-7.

33. Letoublon C, Chen Y, Arvieux C, et al. Delayed celiotomy or laparoscopy as part of the nonoperative management of blunt hepatic trauma. World J Surg. 2008;32:1189-93.

34. Miller PR, Croce MA, Bee TK, Malhotra AK, Fabian TC. Associated injuries in blunt solid organ trauma: implications for missed injury in nonoperative management. J Trauma. 2002;53:238-42

35. Monneuse OJ, Barth X, Gruner L, et al. Les plaies pénétrantes de l'abdomen, conduite diagnostique et thérapeutique. À propos de 79 patients. Ann Chir. 2004;129:156-63.

36. Walt AJ, Wilson RF. Management of trauma: pitfalls and practice. Philadelphia: Lea Febiger; 1975. p. 348.

37. Croce M, Fabian T, Spiers S, et al. Traumatic hepatic artery pseudoaneurysm with hemobilia. Am J Surg. 1994:168:235-8.

38. Pearl LB, Trunkey DD. Compartment syndrome of the liver. J Trauma. 1999; 47:796-8.

\section{Submit your next manuscript to BioMed Central and we will help you at every step:}

- We accept pre-submission inquiries

- Our selector tool helps you to find the most relevant journal

- We provide round the clock customer support

- Convenient online submission

- Thorough peer review

- Inclusion in PubMed and all major indexing services

- Maximum visibility for your research

Submit your manuscript at www.biomedcentral.com/submit

) Biomed Central 